\title{
Expression of three cell adhesion molecules in bladder carcinomas: correlation with pathological features
}

\author{
Agnès Mialhe ${ }^{1, *}$, Josette Louis ${ }^{1}$, Dominique Pasquier ${ }^{2}$, Jean-Jacques Rambeaud ${ }^{3}$ and \\ Daniel Seigneurin ${ }^{1}$ \\ ${ }^{1}$ Groupe de Recherches sur les Tumeurs de Vessie, Institut Albert Bonniot, \\ Université Joseph-Fourier, Grenoble, France \\ ${ }^{2}$ Département d'Anatomo-Pathologie, Centre Hospitalier Universitaire de Grenoble, \\ Grenoble, France \\ ${ }^{3}$ Service d'Urologie, Centre Hospitalier Universitaire de Grenoble, Grenoble, France
}

Received 17 September 1996

Revised 17 December 1996

Accepted 15 January 1997

\begin{abstract}
Recently, independent studies have shown that the expression of two integrin chains, $\beta 4$ and $\alpha 2$, plus the epithelial cadherin are related to tumour progression in human bladder carcinomas. For the first time, we compare the expression of these three cell adhesion molecules using immunohistochemical analysis of consecutive cryosections from a series of 50 bladder tumours. E-cadherin, $\beta 4$, and $\alpha 2$ were strongly expressed in normal urothelium. A majority of non-invasive bladder cancers stained positively for E-cadherin (62\%), whereas only $29 \%$ expressed normal positivity for $\alpha 2$, and only $35 \%$ for $\beta 4$. However, most invasive tumours presented an aberrant expression of $\alpha 2(81 \%), \beta 4(100 \%)$, and E-cadherin $(75 \%)$. We studied the correlation of immunoreactivity with histological grade and stage. The $\alpha 2$ pattern was not correlated with stage and grade. In contrast, loss of normal $\beta 4$ expression was significantly related to increasing tumour grade and deep invasion with a higher correlation for grade. Finally, E-cadherin expression was highly correlated with stage, but not with grade. Thus our results indicate that, although many invasive bladder tumours presented a disorder in expression of the two integrins $\alpha 2$ and $\beta 4$, E-cadherin appeared to be a better marker of invasiveness in bladder carcinomas.
\end{abstract}

Keywords: Bladder cancer, immunohistochemistry, E-cadherin, $\alpha 2$ integrin, $\beta 4$ integrin

\section{Introduction}

Integrins and cadherins are two families of transmembranous glycoproteins that act as cell-surface receptors for the extracellular matrix or for other cell-surface molecules [14,38]. They play a major role during embryonic development and in the maintenance of adult tissue architecture [37]. Experimental

\footnotetext{
${ }^{*}$ Corresponding author: Agnès Mialhe, Groupe de Recherches sur les Tumeurs de Vessie, UPRES "Bases Moléculaires de la Progression Tumorale”, Institut Albert Bonniot, Faculté de Médecine de Grenoble, 38706 La Tronche, Cedex, France. Tel.: +33 4765494 21; Fax: +33 4765494 54; E-mail: agnes.mialhe@ujf-grenoble.fr.
} 
evidence indicates that some of these molecules could function as molecular switches controlling the invasive phenotype [16,44] of tumour cells and the ability of these to metastasise to distant organs [39].

Two forms of urothelial tumours occur: a non-invasive, low stage type that is the most common and which is predisposed to recurrence, and an invasive, high stage type that frequently leads to metastasis [27]. Because of the unpredictable invasiveness potential of bladder tumours, it has become important to find good prognostic parameters. Thus, many recent studies have been carried out to detect the possible relationship between the expression of some cell adhesion molecules and neoplastic progression in bladder cancer. Previous independent studies have shown that expressions of E-cadherin and of two integrin chains, $\alpha 2$ (linked to the $\beta 1$ chain) and $\beta 4$, were disturbed in many invasive bladder cancers, and that these three molecules could be important markers of tumoural progression in neoplastic urothelium $[3,13,21,22,24,25,29]$. They may thus contribute to an invasive phenotype by a loss of their adherence function. E-cadherin is one epithelial specific cadherin that permits intercellular homophylic adherence which is $\mathrm{Ca}^{2+}$ dependent. The $\alpha 2 \beta 1$ complex (also called VLA2) is an intercellular cell adhesion molecule in many epithelial tissues and the $\beta 4$ integrin plays a functional role in the hemidesmosomal anchoring complex and thus plays a role in adherence between the lamina propria and the basal layer of the epithelium. The $\beta 4$ chain is specific to the $\alpha 6 \beta 4$ complex and cannot link with any other $\alpha$ subunit than $\alpha 6$.

The purpose of this investigation was to compare the expression of these molecules on the same kind of bladder tumours and to determine which molecule was the best marker for invasiveness in bladder carcinomas. We demonstrate the immunoreactivity of E-cadherin, $\alpha 2$ integrin, and $\beta 4$ integrin on 50 cancerous bladder tissue sections and comment on our statistical results.

\section{Materials and methods}

\subsection{Specimens}

Neoplastic tissues were obtained from 50 randomly selected transurethral resection specimens submitted to the Department of Pathology, at the Hospital of Grenoble. The 45 male and 5 female patients had a mean age of 67 years, with a range from 39 to 92 years. Informed consent was obtained from each patient included in this study. Eighteen specimens were primary bladder carcinomas and among the 50 patients, 8 received chemotherapy or immunotherapy treatment before the resection. Resection specimens without urothelial tumours were used as normal controls. After excision, tissues were immediately snap-frozen in liquid nitrogen-cooled isopentane and then stored at $-80^{\circ} \mathrm{C}$. The remaining bladder tissue was routinely fixed in $10 \%$ formalin for $24 \mathrm{~h}$ and embedded in paraffin. Carcinoma histological typing was performed on these paraffin embedded samples, according to the criteria of the International Union Against Cancer [12]. Among the invasive tumours, one was a squamous cell carcinoma that was not graded. All other tumours were transitional cell carcinomas which were classified as superficial (pTa-pT1) or invasive $(\mathrm{pT} \geqslant 2)$ tumours and further classed according to histological grades $(1,2$ or 3$)$.

\subsection{Antibodies}

All primary antibodies were mouse monoclonal antibodies: anti-human $\beta 4$ chain, clone AA3, IgG1 (Becton Dickinson France S.A, Pont de Claix, France), anti-human VLA2 alpha chain, clone AK7, IgG1 (Novocastra Laboratories Ltd., Newcastle, United Kingdom), and anti-human E-cadherin (E-CD), clone 6H9, IgG1 (Sanbio, Uden, Netherlands). 


\subsection{Immunohistochemical staining}

A verification of malignancy and sample staging was made by Giemsa staining on the first frozen section. Additional cryostat frozen sections $(8 \mu \mathrm{m})$ on silane treated slides were cut from the OCT (Tissue Tek, Miles Inc., Diagnostics Division, Elkhart, United States) embedded tissue. Immunostaining for E-CD, $\beta 4$ and $\alpha 2$ chains were done on consecutive frozen sections for each tumour sample. For $\beta 4$ and $\alpha 2$ detection, sections were immediately fixed in acetone $\left(10 \mathrm{~min}\right.$ at $\left.-20^{\circ} \mathrm{C}\right)$, air dried and stored at $-20^{\circ} \mathrm{C}$ until use. For E-CD staining, sections were air dried and stored at $-20^{\circ} \mathrm{C}$ without any fixation.

\subsection{1. $\beta 4$ staining}

After rehydration in Tris Buffer Saline 0.1 M pH 7.4 (TBS), non-specific antibody binding was blocked with a $3 \%$ BSA in TBS solution (30 min at room temperature, RT). The blocking solution was drained from the slides and the primary antibody AA3 was applied at a dilution of 1/500 in $0.3 \% \mathrm{BSA}$ in TBS buffer for $1 \mathrm{~h}$ at $37^{\circ} \mathrm{C}$. After washing in $0.3 \%$ BSA-TBS solution, sections were incubated with alkaline phosphatase-conjugated rabbit anti-mouse IgG (DAKO S.A, Trappes, France) at $1 / 25$ in $0.3 \%$ BSA in TBS buffer for $30 \mathrm{~min}$ at RT.

\subsection{2. $\alpha 2$ staining}

The rehydrated section was blocked with $20 \%$ normal rabbit serum (DAKO S.A) in TBS for 20 min at RT and then incubated for 30 min at RT with the primary antibody AK7 diluted at 1/50 in 5\% normal rabbit serum. Between each antibody incubation, slides were washed with TBS and each antibody was diluted in 5\% normal rabbit serum. Immunophosphatase staining was then performed using the streptavidin-biotin-phosphatase technique (DAKO S.A) with biotinylated rabbit anti-mouse $\operatorname{IgG}(1 / 300$ for $30 \mathrm{~min}$ at RT) followed by the streptavidin-biotin-phosphatase complex (30 min at $\mathrm{RT})$.

\subsubsection{E-CD staining}

After rehydration in $0.1 \mathrm{M}$ TBS $\mathrm{pH} 7.4$ supplemented with $1 \mathrm{mM} \mathrm{CaCl}_{2}\left(\mathrm{TBS}^{-\mathrm{Ca}^{2+}}\right)$, frozen sections were fixed with $4 \%$ paraformaldehyde (prepared in $0.1 \mathrm{M}$ phosphate buffer $\mathrm{pH} 7.4$ containing $1 \mathrm{mM} \mathrm{Ca}^{2+}$ ) for $30 \mathrm{~min}$, permeability was increased with $0.2 \%$ Triton X-100 in TBS-Ca ${ }^{2+}$ for $10 \mathrm{~min}$, washed with TBS-Ca ${ }^{2+}$, blocked with normal rabbit serum as for $\alpha 2$ staining, and finally incubated for $1 \mathrm{~h}$ at $37^{\circ} \mathrm{C}$ with the $6 \mathrm{H} 9$ anti-E-CD antibody diluted at $1 / 20$ in $\mathrm{TBS}^{-\mathrm{Ca}^{2+}}$ containing $5 \%$ normal rabbit serum. Then immunostaining was performed as for $\alpha 2$ immunodetection. It must be noted that all washes and dilutions were done in TBS-Ca ${ }^{2+}$.

For immunohistochemical staining, alkaline phosphatase activity was developed with the New Fuchsin substrate (DAKO S.A) for $15 \mathrm{~min}, 6 \mathrm{~min}$, and $12 \mathrm{~min}$, respectively, for $\beta 4, \alpha 2$ and E-CD detection. Sections were finally counterstained with Harris haematoxylin and slides were mounted in aqueous mounting medium Faramount (DAKO S.A). To evaluate the background staining for each immunohistochemistry, negative controls consisted in the primary antibody being replaced by buffer.

\subsection{Evaluation of immunohistochemical staining}

$\beta 4, \alpha 2$, and E-cadherin immunoreactivity were evaluated semi-quantitatively by two independent observers blind to the histological results. As a positive reference, frozen consecutive sections of normal urothelium were immunostained for the three molecules as described above. 


\subsection{1. $\beta 4$ evaluation}

In normal urothelium immunohistochemistry with the anti- $\beta 4$ antibody, an intense and regular staining at the junction of the basal urothelial cells and the lamina propria (Fig. 1E) was obtained. We considered $\beta 4$ immunoreactivity as abnormal when the polarised distribution seen in normal bladder was lost or when the basal membrane of the basal layer presented a reduced staining intensity or a total absence of staining [22].

\subsection{2. $\alpha 2$ evaluation}

Normal urothelial cells showed strong staining for the $\alpha 2$ chain at the cell borders in all epithelial layers (Fig. 1A). Tumours with abnormal expression were negative (i.e., a complete absence of immunoreactivity), heterogeneous (when the tumour was composed of positive and negative cells), or presented a cytoplasmic staining.

\subsubsection{E-CD evaluation}

In normal bladder tissue, E-CD staining was localised on the membrane of all epithelial cells, particularly at cell to cell contacts (Fig. 2A). E-CD expression of tumour specimens was evaluated according to a classification established by Shiozaki et al. [32]. The criteria were: normal (uniformly positive with a high density), heterogeneous (with an important fraction of E-CD-negative cells), and uniformly negative. In some cases we also noticed a cytoplasmic immunoreactivity. When this was associated with negative areas, the tumour was classified as heterogeneous. As E-cadherin has to be present at the cell surface to permit a real homotypic adhesion, cytoplasmic staining could imply that the molecule was non-functional. E-cadherin may be detectable in the cytoplasm either because of a failure to translocate or to anchor in the plasmic membrane, or because of an increased production rate. Thus uniform negative, cytoplasmic, and heterogeneous staining was considered as aberrant expression.

\subsection{Statistical analysis}

For statistical analysis, bladder carcinomas were subdivided into normal or aberrant expression for the three cell adhesion molecules and the $\chi^{2}$ test was used for correlation with pathological data (histological stage and grade). The value of significance was taken as $P<0.05$.

\section{Results}

\subsection{Immunohistochemistry on normal bladder tissue}

The distribution of the three cell adhesion molecules in normal urothelium is illustrated in Figs 1A, $1 \mathrm{E}$, and 2A. Staining for the $\alpha 2$ integrin was strong at the cell-cell borders throughout all layers of the urothelium (Fig. 1A). As has already been reported by Liebert [21] and Southgate [34], we sometimes also noticed an accentuation of the immunoreactivity in the basal cell layers in comparison to the more superficial cells. The localisation of $\alpha 2$ chain at the cell borders was similar to the staining of E-cadherin in normal tissue, suggesting that both these molecules could have a close function in cell to cell adhesion. In fact, the normal urothelium expressed E-cadherin in a uniform and intense array at the intercellular borders, including the superficial cells (Fig. 2A). By contrast the $\beta 4$ chain showed an intense and regular expression in normal urothelium, specifically along the basal lamina at the junction of the basal urothelial cells and the lamina propria (Fig. 1E). 

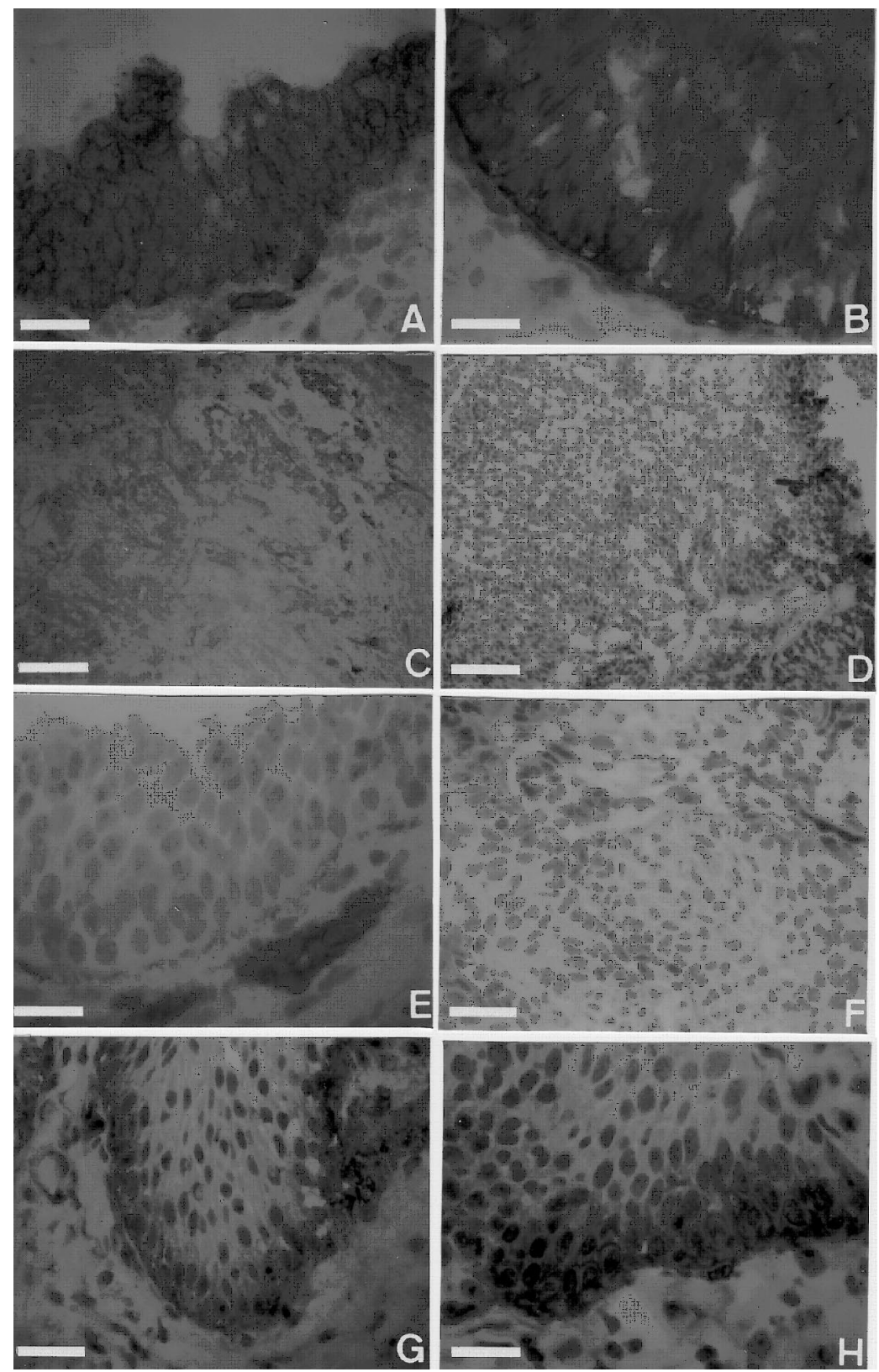

Fig. 1. Patterns of $\alpha 2(\mathrm{~A}-\mathrm{D})$ and $\beta 4(\mathrm{E}-\mathrm{H})$ integrins in normal urothelium and bladder cancer samples. A) Membrane $\alpha 2$ immunoreactivity at cell to cell junctions in all epithelial layers of normal urothelium. B) Superficial tumour with normal $\alpha 2$ expression on cell-cell boundaries. C) Invasive carcinoma with diffuse $\alpha 2$ pattern in cytoplasm of most epithelial cells. D) Loss of $\alpha 2$ expression in superficial bladder cancer: all tumour cells were totally $\alpha 2$ chain negative. (Streptavidin-biotin-phosphatase complex method; A) and B) bars $=20 \mu \mathrm{m}, \times 500$, C) bar $=80 \mu \mathrm{m}, \times 125$ and D) bar $=$ $50 \mu \mathrm{m}, \times 200$.) E) Section of normal bladder tissue with intense and regular $\beta 4$ expression at the junction of basal cells and the lamina propria. The underlying connective tissue is negative except endothelial cells which also express the $\beta 4$ chain. F) Superficial carcinoma with normal $\beta 4$ immunoreactivity as in normal urothelium. G) and H) Tumours with loss of polarisation of the $\beta 4$ integrin: only the basal layer $(\mathrm{G})$ or also in some cases suprabasal layers $(\mathrm{H})$ were positively stained with AA3 antibody. (Indirect immunophosphatase method; E) and F) bars $=15.6 \mu \mathrm{m}, \times 640, \mathrm{G}) \mathrm{bar}=20 \mu \mathrm{m}, \times 500$ and H) bar $=12.5 \mu \mathrm{m}, \times 800$.) 

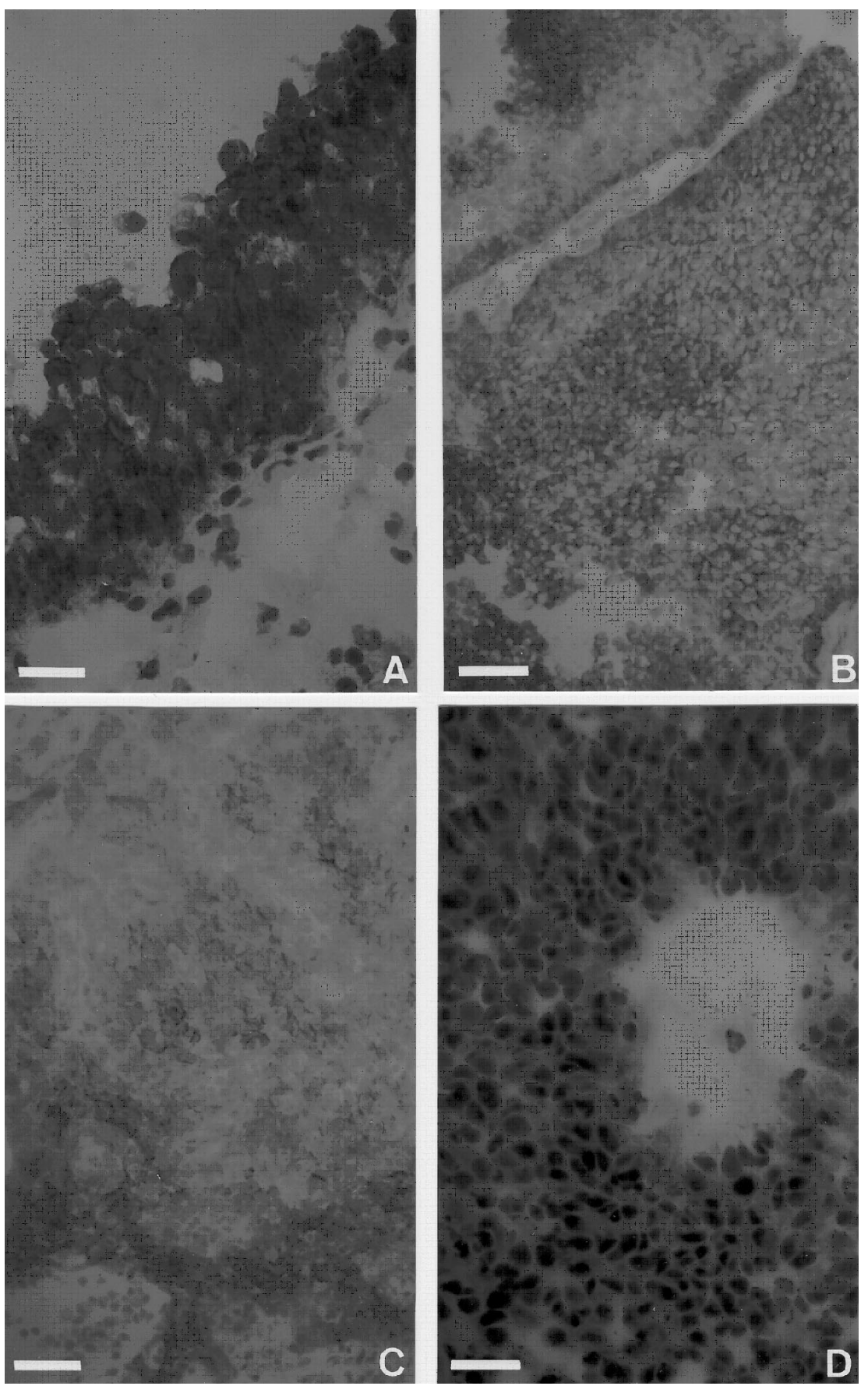

Fig. 2. Immunoreactive E-cadherin expression in normal bladder and cancerous tissues. A) All epithelial cells strongly and homogeneously expressed E-cadherin at cell to cell contacts in normal urothelium. B) Preserved E-cadherin expression in superficial carcinoma. C) Invasive tumour with heterogeneous E-cadherin expression. Some cells were E-cadherin negative whereas the others were normally stained. D) Section of superficial tumour with E-cadherin cytoplasmic staining. (Streptavidin-biotin-phosphatase complex method; A) bar $=12.5 \mu \mathrm{m}, \times 800, \mathrm{~B})$ and C) bars $=50 \mu \mathrm{m}, \times 200$ and D) bar $=$ $20 \mu \mathrm{m}, \times 500$.) 


\subsection{Immunohistochemistry on bladder carcinomas}

Of 50 samples analysed in this study, 34 were superficial tumours (pTa-pT1) and 16 were poorly differentiated invasive carcinomas (pT2-pT3). The repartition by histological grade showed that 13, 14 , and 22 were of grade 1, 2, and 3, respectively (one pT2 tumour was non-graded since it was a squamous carcinoma).

\subsection{1. $\alpha 2$ integrin immunoreactivity}

$29 \%$ of low-stage pTa-pT1 and only $19 \%$ of invasive pT2-pT3 bladder cancer tissues had a normal expression of the $\alpha 2$ chain (Fig. 1B) as seen in normal urothelium (Fig. 1A). Therefore the majority of superficial and most invasive specimens presented an altered expression of the $\alpha 2$ integrin (Table 1). Most of these showed a cytoplasmic immunoreactivity in all epithelial cells (Fig. 1C) while the others were heterogeneous (data not illustrated) or uniformly negative tumours (Fig. 1D).

\subsection{2. $\beta 4$ integrin expression}

Twelve bladder tumours, all superficial carcinomas, had preserved $\beta 4$ expression at the junction of the basal layer and the underlying connective tissue (Fig. 1F) similar to the pattern in normal urothelium (Fig. 1E), while none of the 16 invasive carcinomas had a normal $\beta 4$ immunoreactivity. 22 out of $34(65 \%)$ pTa-pT1 tumours and all the invasive pT2-pT3 carcinomas showed an abnormal pattern of the $\beta 4$ chain (Table 2). The majority of these presented an increased expression of the

Table 1

Relationships of $\alpha 2$ integrin expression to histopathological data

\begin{tabular}{lrrrr}
\hline & \multicolumn{2}{c}{$\alpha 2$ expression } \\
\cline { 2 - 3 } & Normal & Abnormal & \\
\cline { 2 - 3 } & No (\%) & & No $(\%)$ & \\
\hline Stage & & & \\
$\quad$ Superficial pTa-pT1 & $10(29)$ & & $24(71)$ & $P=0.65$ \\
Invasive pT2-pT3 & $3(19)$ & $13(81)$ & $\chi^{2}=0.21$ \\
Grade & & & \\
G1 & $4(31)$ & $9(69)$ & $P=0.47$ \\
G2 & $5(36)$ & $9(64)$ & $\chi^{2}=1.51$ \\
G3 & $4(18)$ & $18(82)$ & \\
\hline
\end{tabular}

Table 2

Relationships of $\beta 4$ integrin expression to histopathological data

\begin{tabular}{|c|c|c|c|}
\hline & \multicolumn{2}{|c|}{$\beta 4$ expression } & \\
\hline & Normal & Abnormal & \\
\hline & No (\%) & No $(\%)$ & \\
\hline \multicolumn{4}{|l|}{ Stage } \\
\hline Superficial pTa-pT1 & $12(35)$ & $22(65)$ & $P=0.017$ \\
\hline Invasive pT2-pT3 & $0 \quad(0)$ & $16(100)$ & $\chi^{2}=5.62$ \\
\hline \multicolumn{4}{|l|}{ Grade } \\
\hline G1 & $8(62)$ & $5(38)$ & $P=0.0007$ \\
\hline $\mathrm{G} 2$ & $3(21)$ & 11 (79) & $\chi^{2}=14.45$ \\
\hline G3 & $1(5)$ & 21 (95) & \\
\hline
\end{tabular}


Table 3

Relationships of E-cadherin expression to histopathological data

\begin{tabular}{lrrrr}
\hline & \multicolumn{3}{c}{ E-cadherin expression } & \\
\cline { 2 - 2 } & Normal & \multicolumn{2}{c}{ Abnormal } & \\
\cline { 2 - 2 } & No (\%) & & No $\%)$ & \\
\hline Stage & & & \\
$\quad$ Superficial pTa-pT1 & $21(62)$ & & $13(38)$ & $P=0.015$ \\
Invasive pT2-pT3 & $4(25)$ & $12(75)$ & $\chi^{2}=5.88$ \\
Grade & & & \\
G1 & $9(69)$ & & $4(31)$ & $P=0.15$ \\
G2 & $8(57)$ & $6(43)$ & $\chi^{2}=3.83$ \\
G3 & $8(36)$ & $14(64)$ & \\
\hline
\end{tabular}

molecule suprabasally with loss of polarisation: the basal membrane of epithelial basal cells, as well as the basal (Fig. 1G) and suprabasal (Fig. 1H) layers were positively stained. Moreover, some tumours showed a weak and irregular staining of the basement membrane, suggesting an interrupted distribution of the $\beta 4$ integrin, or were totally negative, more often in poorly differentiated pT2-pT3 tumours (not illustrated).

\subsubsection{E-cadherin distribution}

Altogether 25 tumours, representing $62 \%$ of pTa-pT1 and $25 \%$ of pT2-pT3 tumours, showed a similar pattern (Fig. 2B) to the normal bladder epithelium (Fig. 2A), i.e., only at the cell-cell borders in the most epithelial cells, whereas the other 25 tumours presented an abnormal E-cadherin expression. Only $38 \%$ of the pTa-pT1 tumours had aberrant E-cadherin expression compared to $75 \%$ of pT2-pT3 specimens (Table 3). Only 2 tumours, which were both classified as pT2G3, were completely negative (data not illustrated). The majority of the others had a heterogeneous immunoreactivity (Fig. 2C), some areas of the tumour being positive and others negative, or in some cases immunostaining was found in the cytoplasm rather than at the cellular membrane (Fig. 2D). Negative, heterogeneous, or cytoplasmic patterns were regarded as aberrant expressions of this molecule.

\subsection{Correlation of the three cell adhesion molecule expression with pathological features}

There was one main objective of the statistical analysis. Considering the putative consequences of loss of one cell adhesion molecule like $\alpha 2, \beta 4$ or E-cadherin, i.e., acquisition of an increased invasive and metastatic potential by the cancerous cells, we aimed to evaluate the relationship between the two integrins and E-cadherin expression and pathological characteristics of the tumour, such as stage and grade (Tables 1-3). This was accomplished by using the $\chi^{2}$ statistical test, in which the null hypothesis of no correlation between molecule expression and stage or grade was rejected at the $P<0.05$ significance level. Confrontation of the $\alpha 2$ chain expression results with the histopathological data (Table 1) revealed that abnormal $\alpha 2$ expression did not correlate with both stage and grade. It predicted that $\alpha 2$ expression was not a good factor for evaluation of invasiveness, since most tumours presented an aberrant expression whether they were of high or low stage or grade. The loss of normal $\alpha 2$ expression may be also rather a marker of malignancy in bladder tissue. By contrast, the association of $\beta 4$ expression loss with increasing tumour grade and deep tumour invasion (Table 2) was statistically significant, with a higher correlation according to the grade. Indeed up to $79 \%$ of grade 2 and $95 \%$ of grade 3 tumours presented an altered expression of the $\beta 4$ chain in comparison to $38 \%$ of grade 1 
(Table 2). Finally no significant differences in E-cadherin expression were found between histological grades 1, 2, and 3. However, the frequency of tumours with abnormal E-cadherin expression was significantly higher in invasive than in well differentiated superficial carcinomas (Table 3).

\section{Discussion}

We studied three important cell adhesion molecules playing a primordial role in maintenance of epithelial integrity, which were $\alpha 2$ and $\beta 4$ integrins, and the epithelial cadherin. In our study, which covered 50 bladder cancer specimens, we demonstrated that the $\alpha 2$ chain is not a good marker for neoplastic progression in bladder cancer. These results concord with those of Liebert et al. [21] for invasive tumours, who used immunofluorescence and found that $76 \%$ of invasive tumours had an aberrant $\alpha 2$ pattern. However, we found more pTa-pT1 tumours with abnormal $\alpha 2$ expression (71\%). $\alpha 2$ immunoreactivity has been not intensively studied in other carcinomas. It has been shown that dedifferentiation of oral squamous cell carcinomas [19], neuroblastomas [8], breast cancers [20], and colorectal carcinomas [35] was accompanied by a decrease in $\alpha 2$ expression.

On the contrary, we demonstrated here that $\beta 4$ integrin expression significantly correlates with both histological stage and grade. As previously reported [22], most bladder carcinomas, whether superficial or invasive, expressed the $\beta 4$ chain in an abnormal pattern. Thus it was difficult to conclude that $\beta 4$ integrin could be a good marker for invasiveness in bladder cancer. A complete loss of the $\beta 4$ subunit has already been demonstrated in prostate carcinomas [6] and breast neoplasms [20]. Loss of the $\beta 4$ integrin appears to be an early marker of malignant transformation because it is downregulated in normal portions of cancerous mammary tissues [15]. On the other hand, we found an increase of $\beta 4$ chain expression for some tumours that is often accompanied by a depolarisation of the molecule. It has been postulated that changes in the phosphorylated state of the $\beta 4$ unit could explain this particular $\beta 4$ distribution [4]. In the present study, although $\beta 4$ expression seemed to be closely related to histological stage, there were many superficial pTa-pT1 tumours with an aberrant $\beta 4$ chain expression, whereas only $38 \%$ pTa-pT1 presented a decreased or disorganised E-cadherin expression.

Thus E-cadherin appeared to be a better marker of invasiveness since 75\% of the pT2-pT3 specimens showed an abnormal E-cadherin expression compared to the majority of superficial tumours which had a preserved E-cadherin immunoreactivity. Whereas we found a weaker statistical significance, our repartition of E-cadherin immunoreactivity according to histopathological stages was close to that found in other studies $[3,24,29]$. However, contrary to these three other published findings, we demonstrated that E-cadherin expression did not significantly correlate with histopathological grades. We are unable to explain this discordance with P.P. Bringuier [3] and J.S. Ross [29], since the number of cases and the repartition of grades was similar to our study. This difference could be due to the fact that we did not study the same tumours. This represents a major issue when studies on tumoural material are compared. On the other hand, Otto et al. [24] have studied a large number of cases $(n=83)$, that could explain the differences in statistical results and repartition. Thus our study confirmed that abnormal E-cadherin expression is a good marker of tumour progression in bladder carcinoma, but additional studies with larger series are needed to elucidate this finding. The number of pT2-pT3 carcinomas studied should be increased to balance the two categories, although superficial pTa-pT1 carcinomas are most commonly observed in patients with bladder cancer [27]. Because of the unpredictable invasive potential of bladder tumours, it becomes important to find a good prognostic parameter. Therefore a survival analysis which requires a large-scale prospective study will allow us to complement our work and so perhaps to evaluate the possible usefulness of E-cadherin as prognostic 
factor in bladder cancer. Recently published results of survival analysis [3,10,24,25] are promising since they showed that abnormal E-cadherin expression correlates strongly with poor prognosis, i.e., showed a strong inverse relation to cancer progression and mortality. Thus these studies revealed the potential of E-cadherin immunohistochemistry as a prognostic tool. We note, however, with surprise, that another recent work [13] on 115 patients showed that E-cadherin expression pattern was not a significant prognostic factor for tumour recurrence and survival.

Loss of E-cadherin expression and significant correlation with histopathological data have been welldescribed in a variety of human carcinomas [32]. Thus, decreased E-cadherin expression has been well correlated with high tumour grade and invasiveness in prostate carcinomas [23] and other studies have demonstrated the prognostic value of E-cadherin staining in these neoplasms $[10,40]$. Recently, many studies showed correlation of E-cadherin expression with differentiation and invasiveness in a variety of neoplasms such as oesophageal [2], colorectal [7], breast [9], pancreatic [26], thyroid [30], cervical [42], gastric [43] cancers, and many others. Moreover, E-cadherin seems to be a prognostic marker in renal [18], thyroid [30], and gastric [43] carcinomas, among others.

It thus seems obvious that E-cadherin is a cell adhesion molecule which plays a primordial function in neoplastic progression of many carcinomas, including bladder carcinomas. But E-cadherin immunoreactivity does not imply that a functional molecule is present. It is possible that some epitopes of the non-functional proteins are recognised by the anti-E-cadherin antibody. The E-cadherin is the central element of the homotypic cell-cell adhesion in epithelium, but E-cadherin function is mediated by three cytoplasmic proteins, $\alpha, \beta$, and $\gamma$ catenins which link E-cadherin to the actin cytoskeleton. It has been shown that some cells do not present homotypic intercellular adhesion since they lack at least one catenin, whereas they have membranous E-cadherin immunoreactivity $[31,41]$. Therefore immunohistochemical co-localisation of E-cadherin and catenins could give some information on the functional state of the catenin-cadherin complex. Lack of $\alpha$-catenin has been observed in many human carcinomas $[28,33,36]$ and was significantly correlated with pathological features in breast [36] and oesophageal [17] carcinomas. Nonetheless, even if some tumours are E-cadherin and catenin positive, some mechanisms implying post-translational phenomena, such as tyrosine phosphorylation on $\beta$-catenin [10,11], may regulate cadherin function. Another mechanism underlying defective E-cadherin function could be mutational inactivation of the E-cadherin gene itself [1] which is located on chromosome 16q22-1, a region which is deleted in certain carcinomas [5]. Moreover different studies have demonstrated a down-regulation of E-cadherin mRNA in various human cancers which could indicate a regulation of the protein expression at the transcription level [7].

In conclusion, our results indicate that, although many invasive bladder specimens present a disorder of $\beta 4$ and $\alpha 2$ expressions, E-cadherin appears to be preferable as a marker for invasiveness according to our series of 50 bladder transitional cell carcinomas. E-cadherin seems to be a good factor of malignant transformation, especially in bladder carcinoma, implying that E-cadherin immunohistochemistry may become useful as a prognostic tool in the near future. It might be interesting to determine E-cadherin expression level by quantitative image analysis methods. However, problems are likely to be encountered for tumour areas where cells express E-cadherin both in the cytoplasm and in cytoplasmic membrane which present considerable differences in integrity and the adhesion function of the protein. Difficulties are to be expected in dissociating cytoplasmic expression, which is an abnormal localisation of the protein, from the normal membranous expression.

\section{Acknowledgments}

The authors thank Ms. Kate Wright for proofreading our manuscript. 


\section{References}

[1] K.F. Becker, M.J. Atkinson, U. Reich, H.H. Huang, H. Nekarda, J.R. Siewert and H. Höfler, Exon skipping in the E-cadherin gene transcript in metastatic human gastric carcinomas, Hum. Mol. Genet. 2 (1993), 803-804.

[2] P.F. Bongiorno, M. Al-Kasspooles, S.W. Lee, W.J. Rachwal, J.H. Moore, R.I. Whyte, M.B. Orringer and D.G. Beer, E-cadherin expression in primary and metastatic thoracic neoplasms and in Barett's oesophagus, Br. J. Cancer 71 (1995), 166-172.

[3] P.P. Bringuier, R. Umbas, H.E. Schaafsma, H.F.M. Karthaus, F.M.J. Debruyne and J.A. Schalken, Decreased E-cadherin immunoreactivity correlates with poor survival in patients with bladder tumors, Cancer Res. 53 (1993), 3241-3245.

[4] T.E. Carey, T.S. Sair, C. Chern, M. Liebert, H.B. Grossman, F.T. Wolf and C. Van Waes, Blood group antigens and integrins as biomarkers in head and neck cancer: is aberrant tyrosine phosphorylation the cause of altered $\alpha 6 \beta 4$ integrin expression?, J. Cell Biochem. 17F (Suppl.) (1993), 223-232.

[5] B.S. Carter, C.M. Ewing, W.S. Ward, B.F. Treiger, T.W. Aalders, J.A. Schalken, J.I. Epstein and W.B. Isaacs, Allelic loss of chromosome 16q and 10q in human prostate cancer, Proc. Natl. Acad. Sci. USA 87 (1990), 8751-8755.

[6] A.E. Cress, I. Rabinovitz, W. Zhu and R.B. Nagle, The $\alpha 6 \beta 1$ and $\alpha 6 \beta 4$ integrins in human prostate cancer progression, Cancer Metastasis Rev. 14 (1995), 219-228.

[7] S. Dorudi, J.P. Sheffield, R. Poulsom, J.M.A. Northover and I.R. Hart, E-cadherin expression in colorectal cancer. An immunohistochemical and in situ hybridization study, Am. J. Pathol. 142 (1993), 981-986.

[8] M.C. Favrot, V. Combaret, E. Goillot, P. Lutz, D. Frappaz, P. Thiesse, A. Thyss, D. Dolbeau, E. Bouffet, E. Tabone and T. Philip, Expression of integrin receptors on 45 clinical neuroblastoma specimens, Int. J. Cancer 49 (1991), 347-355.

[9] C. Gamallo, J. Palacios, A. Suarez, A. Pizarro, P. Navarro, M. Quintanilla and A. Cano, Correlation of E-cadherin expression with differentiation grade and histological type in breast carcinoma, Am. J. Pathol. 142 (1993), 987-993.

[10] L.A. Giroldi, P.P. Bringuier and J.A. Schalken, Detective E-cadherin function in urological cancers: clinical implications and molecular mechanisms, Invasion Metastasis 14 (1994-95), 71-81.

[11] B.M. Gumbiner, Signal transduction by $\beta$-catenin, Curr. Opin. Cell Biol. 7 (1995), 634-640.

[12] P. Hermanek and L.H. Sobin, UICC, TNM Classification of Malignant Tumors, P. Hermanek and L.H. Sobin, eds, Springer-Verlag, Paris, 1988, pp. 143-145.

[13] R.L. Hong, Y.S. Pu, T.S. Hsieh, J.S. Chu and W.J. Lee, Expressions of E-cadherin and exon V6-containing isoforms of CD44 and their prognosis values in human transitional cell carcinoma, J. Urol. 153 (1995), 2025-2028.

[14] R.O. Hynes, Integrins. A family of cell surface receptors, Cell 48 (1987), 549-554.

[15] J.L. Jones, D.R. Critchley and R.A. Walker, Alteration of stromal protein and integrin expression in breast: a marker of premalignant change, J. Pathol. 167 (1992), 399-406.

[16] R.L. Juliano, The role of $\beta 1$ integrins in tumors, Semin. Cancer Biol. 4 (1993), 277-283.

[17] T. Kadowaki, H. Shiozaki, M. Inoue, S. Tamura, H. Oka, Y. Doki, K. Iihara, S. Matsui, T. Iwazawa, A. Nagafuchi, S. Tsukita and T. Mori, E-cadherin and $\alpha$-catenin expression in human esophageal cancer, Cancer Res. 54 (1994), 291-296.

[18] A. Katagiri, R. Watanabe and Y. Yomita, E-cadherin expression in renal call cancer and its significance in metastasis and survival, Br. J. Cancer 71 (1995), 376-379.

[19] H. Kosmehl, A. Berndt, D. Katenkamp, P. Hyckel, K.J. Stiller, U. Gabler, L. Langbein and T. Reh, Integrin receptors and their relationship to cellular proliferation and differentiation of oral squamous cell carcinoma. A quantitative immunohistochemical study, J. Oral Pathol. Med. 24 (1995), 343-348.

[20] G.K. Koukoulis, I. Virtanen, M. Korhonen, L. Laitinen, V. Quaranta and V.E. Gould, Immunohistochemical localization of integrins in the normal, hyperplastic, and neoplastic breast. Correlations with their functions as receptors and cell adhesion molecules, Am. J. Pathol. 139 (1991), 787-799.

[21] M. Liebert, R. Washington, J. Stein, G. Wedemeyer and H.B. Grossman, Expression of the VLA $\beta 1$ integrin family in bladder cancer, Am. J. Pathol. 144 (1994), 1016-1022.

[22] M. Liebert, R. Washington, G. Wedemeyer, T.E. Carey and H.B. Grossman, Loss of co-localization of $\alpha 6 \beta 4$ integrin and collagen VII in bladder cancer, Am. J. Pathol. 144 (1994), 787-795.

[23] T. Otto, K. Rembrick, M. Goepel, M. Meyer-Schwickerath and H. Rubben, E-cadherin: a marker for differentiation and invasiveness in prostatic carcinoma, Urol. Res. 21 (1993), 359-362.

[24] T. Otto, W. Birchmeier, U. Schmidt, A. Hinke, J. Schipper, H. Rübben and A. Raz, Inverse relation of E-cadherin and autocrine motility factor receptor expression as a prognostic factor in patients with bladder carcinomas, Cancer Res. 54 (1994), 3120-3123.

[25] T. Otto, M. Goepel, K.H. Heider and H. Rübben, Prognostic factors for bladder cancer, Urol. Res. 23 (1995), 137-141.

[26] M. Pignatelli, T.W. Ansari, P. Gunter, D. Liu, S. Hirano, M. Takeichi, G. Klöppel and N.R. Lemoine, Loss of membranous E-cadherin expression in pancreatic cancer: correlation with lymph node metastasis, high grade, and advanced stage, J. Pathol. 174 (1994), 243-248. 
[27] D. Raghavan, W.U. Shipley, M.B. Garnick, P.J. Russel and J.P. Richie, Biology and management of bladder cancer, N. Engl. J. Med. 322 (1990), 1129-1138.

[28] D.L. Rimm, J.H. Sinard and J.S. Morrow, Reduced $\alpha$-catenin and E-cadherin expression in breast cancer, Lab. Invest. 72 (1995), 506-512.

[29] J.S. Ross, A.D. Del Rosario, H.L. Figge, C. Sheehan, H.A.G. Fisher and H.X. Bui, E-cadherin expression in papillary transitional cell carcinoma of the urinary bladder, Hum. Pathol. 26 (1995), 940-944.

[30] G.F.W. Scheumman, C. Hoang-Vu, Y. Cetin, O. Gimm, J. Behrends, R. Von Wasielewski, A. Georgii, W. Birchmeier, A. Von Zur Mühlen, H. Dralle and G. Brabant, Clinical significance of E-cadherin as a prognostic marker in thyroid carcinomas, J. Clin. Endocrinol. Metabol. 80 (1995), 2168-2172.

[31] Y. Shimoyama, A. Nagafuchi, S. Fujita, M. Gotoh, M. Takeichi, S. Tsukita and S. Hirohashi, Cadherin dysfunction in a human cancer cell line: possible involvement of loss of $\alpha$-catenin expression in reduced cell-cell adhesiveness, Cancer Res. 52 (1992), 5770-5774.

[32] H. Shiozaki, H. Tahara, H. Oka, M. Miyata, K. Kobayashi, S. Tamura, K. Iihara, Y. Doki, S. Hirano, M. Takeichi and T. Mori, Expression of immunoreactive E-cadherin adhesion molecules in human cancers, Am. J. Pathol. 139 (1991), $17-23$.

[33] H. Shiozaki, K. Iihara, H. Oka, T. Kadowaki, S. Matsui, J. Gofuku, M. Inoue, A. Nagafuchi, S. Tsukita and T. Mori, Immunohistochemical detection of $\alpha$-catenin expression in human cancers, Am. J. Pathol. 144 (1994), 667-674.

[34] J. Southgate, W. Kennedy, K.A.R. Hutton and L.K. Trejdosiewicz, Expression and in vitro regulation of integrins by normal human urothelial cells, Cell Adhes. Commun. 3 (1995), 231-242.

[35] A. Stallmach, B.V. Lampe, H. Matthes, G. Bornhöft and E.O. Riecken, Diminished expression of integrin adhesion molecules on human colonic epithelial cells during the benign to malign tumour transformation, Gut 33 (1992), $342-346$.

[36] T. Takayama, H. Shiozaki, M. Inoue, S. Tamura, H. Oka, T. Kadowaki, Y. Takatsuka, A. Nagafuchi, S. Tsukita and T. Mori, Expression of E-cadherin and $\alpha$-catenin molecules in human breast cancer tissue and association with clinicopathological features, Int. J. Oncol. 5 (1994), 775-780.

[37] M. Takeichi, The cadherins: cell-cell adhesion molecules controlling animal morphogenesis, Development 102 (1988), 639-655

[38] M. Takeichi, Cadherin cell adhesion receptors as a morphogenetic regulator, Science 251 (1991), 1451-1455.

[39] D.G. Tang and K.V. Honn, Adhesion molecules and tumor metastasis: an update, Invasion Metastasis 14 (1994-95), 109-122.

[40] R. Umbas, W.B. Isaacs, P.P. Bringuier, H.E. Schaafsma, H.F.M. Karthaus, G.O.N. Oosterhof, F.M.J. Debruyne and J.A. Schalken, Decreased E-cadherin expression is associated with poor prognosis in patients with prostate cancer, Cancer Res. 54 (1994), 3929-3933.

[41] S.J. Vermeulen, E.A. Bruyneel, M.E. Bracke, G.K. De Bruyne, K.M. Vennekens, K.L. Vleminckx, G.J. Berx, F.M. Van Roy and M.M. Mareel, Transition from the noninvasive to the invasive phenotype and loss of $\alpha$-catenin in human colon cancer cells, Cancer Res. 55 (1995), 4722-4728.

[42] C.J. Vessey, J. Wilding, N. Folarin, S. Hirano, M. Takeichi, P. Soutter, G.W.H. Stamp and M. Pignatelli, Altered expression and function of E-cadherin in cervical intraepithelial neoplasia and invasive squamous cell carcinoma, J. Pathol. 176 (1995), 151-159.

[43] Y. Yonemura, N. Nojima, M. Kaji, T. Fujimura, H. Itoh, I. Ninomiya, I. Miyazaki, Y. Endo and T. Sasaki, E-cadherin and urokinase-type plasminogen activator tissue status in gastric carcinoma, Cancer 76 (1995), 941-953.

[44] M.M. Zutter, S.A. Santoro, W.D. Staatz and Y.L. Tsung, Re-expression of the $\alpha 2 \beta 1$ integrin abrogates the malignant phenotype of breast carcinoma cells, Proc. Natl. Acad. Sci. USA 92 (1995), 7411-7415. 


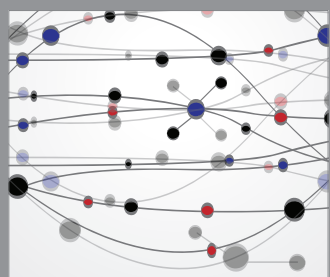

The Scientific World Journal
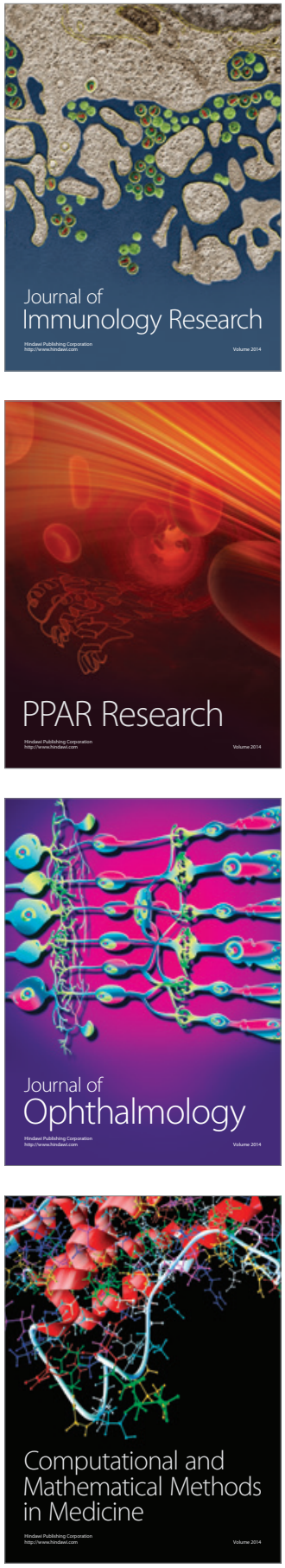

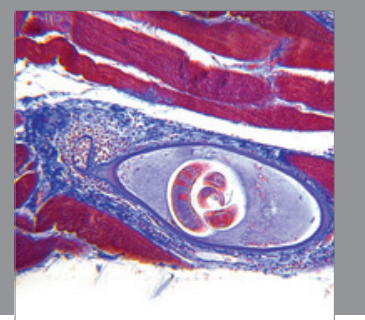

Gastroenterology

Research and Practice
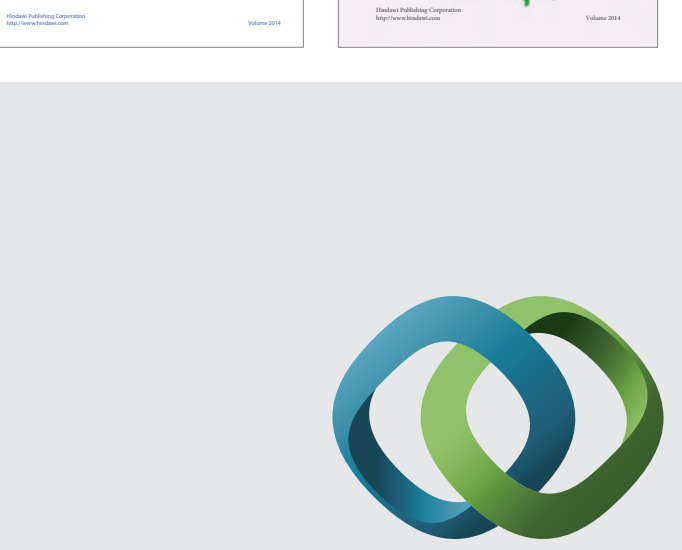

\section{Hindawi}

Submit your manuscripts at

http://www.hindawi.com
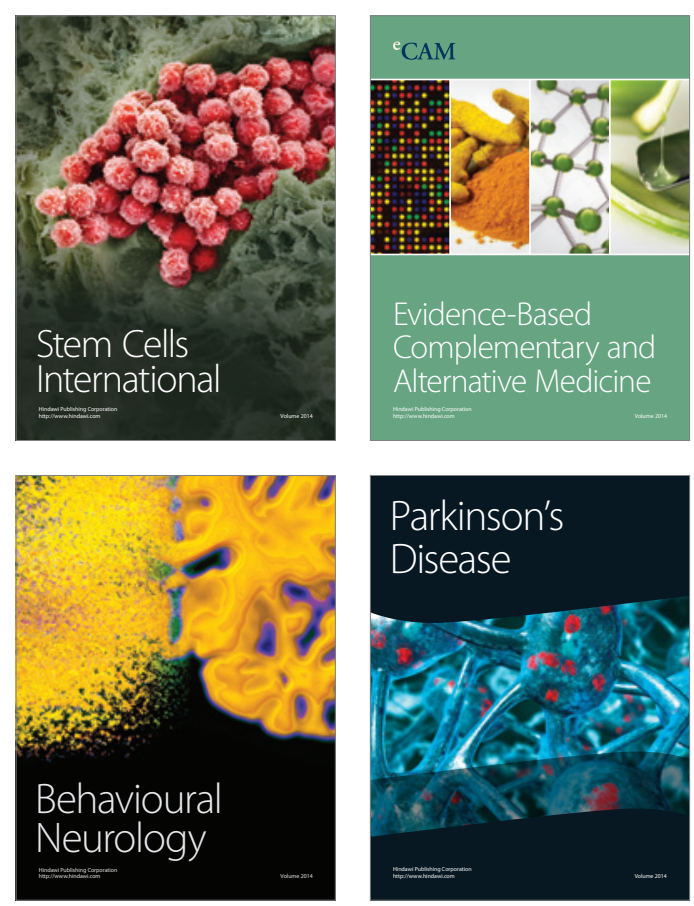

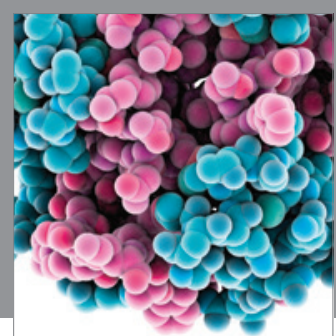

Journal of
Diabetes Research

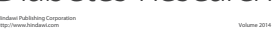

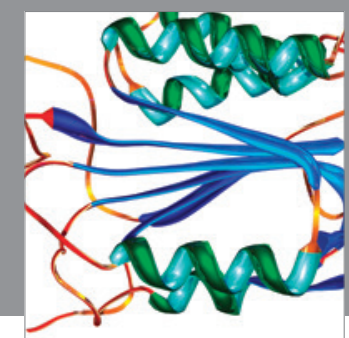

Disease Markers
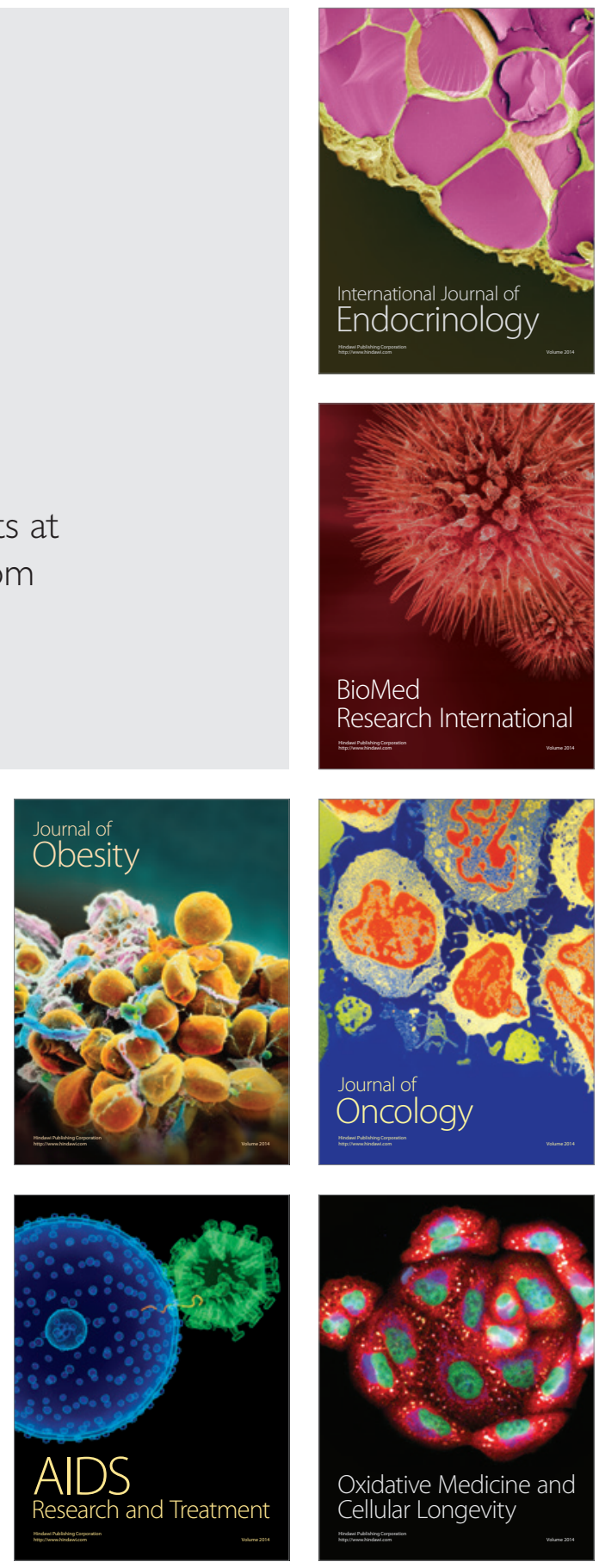